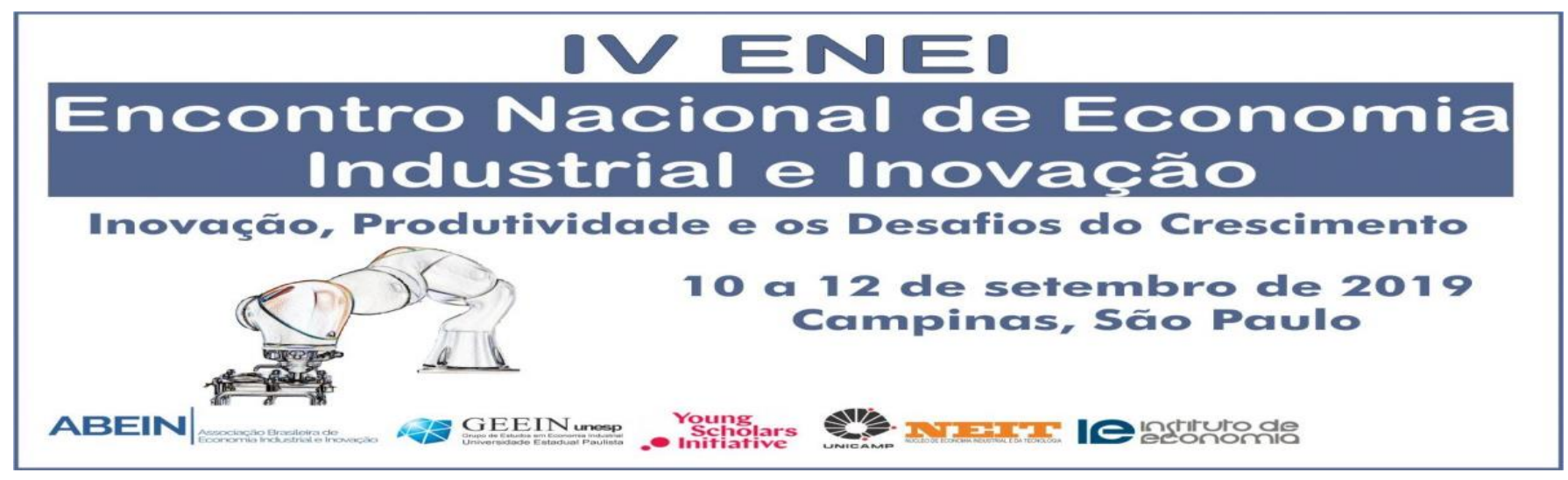

\title{
TECNOLOGIAS DA INDÚSTRIA 4.0 E AGRONEGÓCIO: uma reflexão para um conjunto de firmas do Rio Grande do Sul.
}

\author{
Rodrigo Ferneda \\ Mestre pelo Programa de Pós-Graduação em Economia pela Universidade do Vale do Rio dos Sinos (UNISINOS) \\ E-mail: rodrigo_ferneda@hotmail.com \\ Janaína Ruffoni \\ Professora do Programa de Pós-Graduação em Economia pela Universidade do Vale do Rio dos Sinos (UNISINOS) \\ E-mail: jruffoni@unisinos.br
}

\section{RESUMO}

O objetivo do estudo é compreender a adoção de tecnologias da indústria 4.0 em firmas do agronegócio do Rio Grande do Sul (RS). Uma pesquisa exploratória e qualitativa foi realizada. Foram investigadas firmas adotantes deste tipo de tecnologia, instituições e especialistas com quatorze entrevistas semiestruturadas realizadas em 2017. Os resultados apontaram que as tecnologias adotadas são big data, internet das coisas e robótica. As adotantes são firmas multinacionais, de grande porte, localizadas na região metropolitana de Porto Alegre e atuantes na fase pré porteira. A exceção está em uma firma que é familiar, localizada no interior do RS. As instituições têm papel fundamental, contribuindo para a qualificação de recursos humanos e tecnológicos, desenvolvimento de testes de protótipos, máquinas e equipamentos e em consultorias em projetos de parceria público-privado. Para que a adoção seja mais difundida são necessários esforços diversos por parte de diferentes atores.

Palavras-chave: Adoção de tecnologias. Tecnologias da indústria 4.0. Firmas do agronegócio. Atores.

\begin{abstract}
The objective of the study is to understand the adoption of 4.0 industry technologies in agribusiness firms in the Rio Grande do Sul (RS). Exploratory and qualitative research was carried out. We have investigated the adopters of this type of technology, institutions, and specialists with fourteen semistructured interviews conducted in 2017. The results showed that the adopted technologies are big data, internet of things and robotics. The adopters are large multinational firms located in the metropolitan area of Porto Alegre and active in the pre-port phase. The exception is in a firm that is familiar, Brazilian, situated in the interior of the RS. Institutions play a crucial role, contributing to the qualification of human and technological resources, development of prototype tests, machines and equipment, and consulting in public-private partnership projects. For the adoption to be more extensive, diverse efforts are required by different actors profiles.
\end{abstract}

Keywords: Adoption of technologies. Industry technologies 4.0. Agribusiness firms. Actors.

Jel.: O14; O33; O39.

Área ENEI: 5.5 - Mudanças técnicas, organizações e instituições 


\section{TECNOLOGIAS DA INDÚSTRIA 4.0 E AGRONEGÓCIO: uma reflexão para um conjunto de firmas do Rio Grande do Sul ${ }^{1}$}

\section{Introdução}

A economia neo shumpeteriana ou evolucionária tem como preocupação a dinâmica da firma capitalista e a inovação como um processo endógeno. Essa lógica, apresentada de forma estruturada na obra de Schumpeter, tem seguidores como, Richard Nelson, Sidney Winter, Giovanni Dosi, Nathan Rosenberg, entre outros, conhecidos como neo-schumpeterianos. De forma geral, a compreensão é que a geração, absorção, adaptação e transferências de conhecimentos e tecnologias são ações promotoras de dinâmica econômica, concorrência empresarial e de desenvolvimento.

Neste contexto, desperta curiosidade saber como ocorre a adoção de tecnologias consideradas portadoras de futuro. A indústria 4.0 é constituída por um conjunto de tecnologias que permite bens e serviços serem produzidos em fábricas inteligentes, com comunicação e disponibilidade de informações em tempo real, promovendo a criação de valor, novos modelos de negócios e serviços como mencionado nos estudos de Kagermann et al. (2013), Bauer (2014), Heng (2014), Sheer (2015) e Rubamannet et al (2015).

Estas tecnologias já estão sendo adotadas em diversos segmentos produtivos de países desenvolvidos como Alemanha, Estados Unidos, Europa, França, como mencionado no estudo de (KAGERMANN et al. 2013). Um dos setores que pode ser beneficiado na adoção de tecnologias da indústria 4.0 é o agronegócio, como é o caso da União Europeia (SCHRIJVER, 2016). O relatório apresentado pelo Cema (European Agricultural Machinery, 2016), informa que essas tecnologias atuam por meio de sensores, microprocessadores de baixo custo e comunicação baseada em nuvem. As indústrias antes da porteira, ou seja, de máquinas e implementos agrícolas, adotam, por meio de dispositivos de controle inteligentes, sensores para a operação da máquina, com capacidades avançadas de automação e comunicação entre os processos. Na mesma avaliação, constata-se ainda que existem informações em formato digital para vários setores e processos agrícolas, comunicação com parceiros externos, como clientes e fornecedores de forma eletrônica, por meio da transmissão, processamento e análise dos dados. Os benefícios da adoção de tecnologias para a indústria 4.0 para o setor do agronegócio concentram-se no desenvolvimento dos empregos intelectuais, equipes interdisciplinares, integração e conecção entre máquinas, peças, sistemas e seres humanos, agregação de valor aos processos e produtos finais, como descritos por Bauer (2014), Monostori (2014), Posada et al. (2015), Stock e Seliger (2016).

Nesse contexto, o presente trabalho busca identificar e analisar o processo de adoção das tecnologias da indústria 4.0 por firmas do agronegócio do Rio Grande do Sul. A hipótese trabalhada é que as tecnologias da indústria 4.0 contribuem para o agronegócio por meio da introdução de inovações capazes de estimular a diferenciação e agregação de valor aos produtos finais (HENG, 2014). O objeto de estudo é a firma, porém, adota-se uma visão sistêmica considerando que a empresa, por estar inserida em um contexto institucional, relaciona-se com vários outros agentes. Sendo assim, considerou-se fundamental a inclusão de outros atores no processo de investigação.

$\mathrm{O}$ artigo está dividido em outros quatro seções. Inicia-se a segunda seção com uma revisão da literatura a cerca da adoção de tecnologia pelas firmas; conceitos sobre tecnologias da indústria 4.0 e as firmas do agronegócio gaúcho que adotam as referidas tecnologias. Na terceria seção, apresenta-se os procedimentos metodológicos, demonstrando as técnicas adotadas para a concretização do estudo. Na quarta seção, são apresentados os resultados, podendo confrontar os elementos teóricos com os dados encontrados diante da temática da adoção, Por fim, são feitas as considerações finais.

\section{Adoção tecnológica pelas firmas}

Desde os anos de 1970, vários estudos de inovação organizacional foram discutidos com foco na adoção de tecnologias. Através dos autores Zaltman et al (1973), Daft (1982), Damanpour e Evan (1984) constatou-se que a adoção da inovação surge por meio de uma modificação radical ou incremental de um

\footnotetext{
${ }^{1}$ Agradecemos as contribuições das bolsistas de Iniciação Científica.
} 
produto, serviço, dispositivo, política ou programa, rompendo com a lógica tradicional de trabalho, possibilitando novas rotinas para a firma adotante.

Na visão de Kruglianskas (1996) e Damanpour (2001), a temática está baseada no processo em que a firma se adapta ao ambiente, antecipando-se às mudanças, como forma de aumentar sua competitividade, por meio do aumento da participação do mercado, satisfação do cliente, diferenciandose, assim, da concorrência. No estudo de Possas (2008), essa adoção gera inovações para a firma, por meio de novas rotinas que induzem a uma maior lucratividade, em um processo de seleção pelo mercado.

Diante da trajetória dos estudos de adoção da inovação nas firmas, destaca-se as tendências das tecnologias e seu impacto no processo produtivo, em que envolve uma série de variáveis que não estão sob o controle da firma. A decisão da escolha da tecnologia depende da atividade econômica, capacidade inovativa e participação da mão de obra interna e terceirizada para sua efetividade. O desenvolvimento do processo de adoção das tecnologias ocorre através das características particulares de cada firma, a mão de obra para seu desenvolvimento, o papel do Estado e dos atores institucionais como elementos fundamentais na decisão da firma em inovar. Destacam-se ainda, as dificuldades encontradas no processo de adoção, sendo uma barreira que a firma identifica no ambiente na qual estão inseridas. Contudo, os resultados em produtos e processos e resultados econômicos constituem os elementos finais do processo de adoção. O Quadro 1, apresenta a síntese, apresentando as categorias, suas dimensões e os autores envolvidos.

Quadro 1: Síntese das categorias que proporcionam a adoção de tecnologias pela firma

\begin{tabular}{|c|c|c|c|}
\hline Identificação & Categorias & Dimensões & Autores \\
\hline \multirow[t]{2}{*}{ Porquê } & Tendências & $\begin{array}{l}\text { Quando a firma decide adotar uma nova tecnologia, observa } \\
\text { várias questões pertinentes, como: as preocupações, as incertezas, } \\
\text { condições de mercado, a provável resposta dos consumidores à } \\
\text { nova tecnologia, concorrência, custos, investimentos, capacitação } \\
\text { da mão de obra. }\end{array}$ & $\begin{array}{l}\text { Farzin et al } \\
(1998)\end{array}$ \\
\hline & Escolha tecnológica & $\begin{array}{l}\text { A escolha da adoção depende de quanto a tecnologia irá avançar } \\
\text { ao longo do tempo. } \\
\text { As firmas inovadoras do mesmo setor são heterogêneas, pois, as } \\
\text { que estão aptas a mudança, encontram-se na fronteira tecnológica, } \\
\text { sendo os primeiros adotantes, motivados pela oportunidade de } \\
\text { ganho social e econômico, e que as adotantes posteriores são } \\
\text { motivadas pela ameaça da perda de competitividade. } \\
\text { Envolve a participação dos gestores, colaboradores, consultores, } \\
\text { que definem as prioridades e especifica os sistemas de seleção e } \\
\text { fornecedores. }\end{array}$ & $\begin{array}{l}\text { Massini, Henrich } \\
\text { e Greve (2005) } \\
\text { Engsfelt e } \\
\text { Nordgren, } \\
\text { (2014). }\end{array}$ \\
\hline \multirow[t]{2}{*}{ Como } & $\begin{array}{l}\text { Características e } \\
\text { peculiaridades da } \\
\text { firma e da } \\
\text { tecnologia }\end{array}$ & $\begin{array}{l}\text { Iniciativas de marketing, recursos humanos, mudança cultural, } \\
\text { expansão tecnológica, são determinantes para o planejamento da } \\
\text { firma, via adoção de tecnologia. Destaca-se também, a } \\
\text { financiamento para expansão da capacidade de infraestrutura e } \\
\text { capacidade produtiva da firma, com a finalidade de melhorar a } \\
\text { aceleração da adoção. } \\
\text { Características importantes das inovações que explicam sua taxa } \\
\text { de adoção, através do relacionamento social, relações de mercado, } \\
\text { influência ambiental, experiências, valores e identidade } \\
\text { organizacional da firma, práticas, estrutura, tamanhos. } \\
\text { Integra vários atores do sistema organizacional. A inovação de } \\
\text { uma firma, estimula outras a adotarem. }\end{array}$ & $\begin{array}{l}\text { Kimberly e } \\
\text { Evaniska (1981) } \\
\text { Langley e Truax } \\
\text { (1994) } \\
\text { Rogers (1994), } \\
\text { Frambach e } \\
\text { Schillewaert } \\
(2002)\end{array}$ \\
\hline & Mão de obra & $\begin{array}{l}\text { Rede com desenvolvedores e consultores; normas, valores e } \\
\text { cultura; tamanho e estrutura operacional; treinamento e } \\
\text { desenvolvimento de esforços; liderança; prontidão para a } \\
\text { mudança; o interesse da firma em controle da qualidade e } \\
\text { reengenharia podem melhorar a eficiência e permitir a adoção de } \\
\text { inovação de processo. } \\
\text { Quanto maior a qualificação da mão de obra, mais inovativa pode } \\
\text { torna-se a firma. }\end{array}$ & $\begin{array}{l}\text { Damanpour } \\
(2001) \\
\text { Wisdom et al } \\
(2014) \text {. } \\
\text { Buzzacchi, et al } \\
(1993) .\end{array}$ \\
\hline
\end{tabular}




\begin{tabular}{|c|c|c|c|}
\hline & Papel do Estado & $\begin{array}{l}\text { Setor governamental que determina a renda investida pelos } \\
\text { grupos de governo com o objetivo incentivar o investimento da } \\
\text { firma em uma tecnologia mais avançada. }\end{array}$ & $\begin{array}{l}\text { Parente e Prescott } \\
\text { (1994) }\end{array}$ \\
\hline & Atores institucionais & $\begin{array}{l}\text { Influência externa e sócio-política, por meio do ambiente em que } \\
\text { as firmas estão inseridas, as políticas, regulamentos, normas, } \\
\text { incentivos financeiros e apoio institucional são condições para } \\
\text { promover a adoção. }\end{array}$ & $\begin{array}{l}\text { Wisdom et al } \\
(2014)\end{array}$ \\
\hline & \multirow[t]{2}{*}{$\begin{array}{l}\text { Dificuldades } \\
\text { internas }\end{array}$} & $\begin{array}{l}\text { Restrições legais e regulamentares, decisão dos colaboradores. } \\
\text { Destaca-se o conhecimento geral e científico e tecnológico e o } \\
\text { tamanho das barreiras à adoção da firma. }\end{array}$ & $\begin{array}{l}\text { Parente e Prescott } \\
\text { (1994) }\end{array}$ \\
\hline & & $\begin{array}{l}\text { Inclui os fatores internos, como a atitude e a percepção de como } \\
\text { adotar a tecnologia, financiamento. }\end{array}$ & Rogers (1994) \\
\hline & \multirow[t]{2}{*}{$\begin{array}{l}\text { Dificuldades } \\
\text { externas }\end{array}$} & $\begin{array}{l}\text { Depende da capacidade produtiva e dos investimentos, e da saída } \\
\text { de tecnologia e que define o tamanho da barreira à adoção no País } \\
\text { em que firma está localizada. Isso reflete em várias ações que o } \\
\text { poder público pode incentivar a firma a adotar uma tecnologia } \\
\text { mais avançada. }\end{array}$ & $\begin{array}{l}\text { Farzin et al } \\
\text { (1998) } \\
\text { Parente e Prescott } \\
\text { (1994). }\end{array}$ \\
\hline & & $\begin{array}{l}\text { Disponibilidade técnica e acessibilidade e apoio institucional. } \\
\text { Menciona o papel da universidade, suporte técnico, assessoria, } \\
\text { grupos de interesse, mão de obra qualificada, financiamento, } \\
\text { treinamento e desenvolvimento de pessoas, hardware, software. }\end{array}$ & Rogers (1994) \\
\hline \multirow[t]{2}{*}{ Resultados } & $\begin{array}{l}\text { Resultado da } \\
\text { inovação }\end{array}$ & $\begin{array}{l}\text { Inovação em produtos: as firmas bem-sucedidas integram os } \\
\text { processos produtivos com o conhecimento, criando vantagem } \\
\text { competitiva. } \\
\text { Exige que a firma assimile a necessidade dos clientes para } \\
\text { desenvolver e produzir o produto. } \\
\text { Inovação em processos: a firma adota tecnologia para melhorar a } \\
\text { eficácia de desenvolvimento de produto e comercialização } \\
\text { Proporciona novos métodos de gestão de recursos humanos, } \\
\text { design de novos produtos }\end{array}$ & $\begin{array}{l}\text { Ettlie et al } \\
(1984) . \\
\text { Ettlie e Reza } \\
(1992) . \\
\text { Langley e Truax } \\
\text { (1994). }\end{array}$ \\
\hline & $\begin{array}{l}\text { Resultado } \\
\text { econômico }\end{array}$ & $\begin{array}{l}\text { Destaca que o retorno do investimento, é considerado um } \\
\text { elemento importante na decisão da firma em adotar tecnologia, } \\
\text { O apoio financeiro é fundamental para o dimensionamento dos } \\
\text { resultados econômicos e de potencial de mercado, podem ser } \\
\text { oriundos de recursos próprios da firma, recursos externos, como } \\
\text { por exemplo, subsídio do governo ou empréstimos, capital de } \\
\text { risco, empréstimo bancário. } \\
\text { Uma adoção inadequada é um custo irrecuperável; não pode ser } \\
\text { transferido para um investimento em outra tecnologia mais } \\
\text { eficiente em um segundo momento, devido ao alto custo de } \\
\text { oportunidade de investimento a curto prazo. }\end{array}$ & $\begin{array}{l}\text { Parente e Prescott } \\
\text { (1994); } \\
\text { Langley e Truax } \\
\text { (1994) } \\
\text { Farzin et al } \\
\text { (1998). }\end{array}$ \\
\hline
\end{tabular}

Fonte: elaboração própria.

No Quadro 1 foram apresentadas as etapas necessárias para a firma adotar tecnologia, baseado na literatura investigada. Nesse sentido, utilizou-se a síntese deste Quadro como roteiro para a elaboração da investigação empírica.

\subsection{Tecnologias da indústria 4.0}

O termo 'tecnologias da indústria 4.0', surgiu na Alemanha em 2011 quando Kagermann, Lukas e Wahlster, representantes de negócios na Feira em Hannover que identificaram uma mudança paradigmática na indústria alemã. Essas tecnologias foram responsáveis pela manutenção estável do número de empregados na economia num período de 10 anos, não apresentando dificuldades em manterem-se ativas na indústria durante o período de enfrentamento da crise financeira internacional (KAGERMANN, 2011).

A Alemanha estabeleceu uma posição de liderança internacional em sistemas integrados, em soluções de segurança e em software empresarial. Ainda, o País deseja, ser pioneiro no desenvolvimento 
de sistemas ciber-físicos (CPS), que fornecem dados para a criação da Internet das Coisas. (KAGERMANN, LUKAS e WAHLSTER, 2011), tornando-se destaque sobre a temática (SHEER, 2015), gerando maior valor agregado, em inúmeros setores, (HENG, 2014) particularmente na engenharia automotiva e mecânica (KAGERMANN, LUKAS e WAHLSTER, 2011). Diante deste conjunto tecnológico, voltam-se as estimativas de que o país tornar-se-á pioneiro em 2020, ou seja, líder no fornecimento de equipamentos desta indústria para outras nações (KAGERMANN, LUKAS e WAHLSTER, 2011) e fará com que os sistemas de produção operem até $30 \%$ mais rápido e $25 \%$ mais eficiente, elevando a personalização em massa a novos níveis da firma (RUBAMANN, et al 2015). Além destes autores, Schwab (2016) destaca a geração de oportunidades de integração da economia global, criando demandas adicionais para serviços e produtos existentes, através da conectividade, redução de custos e da orientação de novos modelos de negócios.

Rubamann et al (2015) apresenta um conjunto de nove tecnologias que compõem a temática em estudo: Big Data and Analytics, Robôs Autônomos (Autonomous Robots), Simulação (Simulation), Integração Horizontal e Vertical de Sistemas (Horizontal and Vertical System Integration), Internet Industrial das Coisas (The Industrial Internet of Things), Segurança Cibernética (Cybersecurity), A Nuvem (The Cloud), Manufatura Aditiva ou Impressão em 3D (Additive Manufacturing), Realidade aumentada (Augmented reality)

Com base no exposto, o Quadro 2 apresenta uma sistematização do conjunto de tecnologias da Indústria 4.0, suas características e alguns impactos causados.

Quadro 2: Tecnologias da Indústria 4.0

\begin{tabular}{|c|c|c|}
\hline Tecnologias & Características & Impactos gerados \\
\hline Big Data & $\begin{array}{l}\text { Otimização a qualidade da produção, } \\
\text { economia de energia e melhoramento nos } \\
\text { serviços de saúde. }\end{array}$ & $\begin{array}{l}\text { Diferentes equipamentos e sistemas de produção; } \\
\text { Sistemas de gestão empresarial e sistema de gestão de } \\
\text { clientes; } \\
\text { Decisão em tempo real. }\end{array}$ \\
\hline $\begin{array}{l}\text { Robôs } \\
\text { Autônomos }\end{array}$ & $\begin{array}{l}\text { Agregação de valor nos processos } \\
\text { operacionais; } \\
\text { Interação entre robótica e humanos; } \\
\text { Sensores } \\
\text { Volume de informações de posições e } \\
\text { objetos, com base em informações de } \\
\text { forma física e virtual. }\end{array}$ & $\begin{array}{l}\text { Produção enxuta; } \\
\text { Controla a capacidade crescente; } \\
\text { Eficiência na produção; } \\
\text { Comunicação entre homem, máquina e recursos para o } \\
\text { processo de fabricação. }\end{array}$ \\
\hline Simulação & $\begin{array}{l}\text { Alavancagem de dados em tempo real; } \\
\text { Espelhar o mundo físico em um mundo } \\
\text { virtual; } \\
\text { Integração de máquinas, produtos e } \\
\text { humanos. }\end{array}$ & $\begin{array}{l}\text { Testar e otimizar as definições da linha de produto próximo } \\
\text { no mundo virtual; } \\
\text { Redução dos tempos de configuração da máquina; } \\
\text { Aumenta a qualidade. }\end{array}$ \\
\hline $\begin{array}{l}\text { Integração de } \\
\text { Sistemas } \\
\text { Horizontal e } \\
\text { Vertical }\end{array}$ & $\begin{array}{l}\text { Horizontal: inter-relação da indústria com } \\
\text { a ligação dos processos de produção. } \\
\text { Novos modelos de negócios } \\
\text { Vertical: aumento da qualidade e } \\
\text { flexibilidade; } \\
\text { Estrutura de produção não fixa e } \\
\text { predefinida. }\end{array}$ & $\begin{array}{l}\text { Horizontal: gerenciar o fluxo de bens e informações dentro } \\
\text { da cadeia de valor, através da cooperação entre firmas; } \\
\text { Vertical: processamento em tempo real; } \\
\text { Auto-organização, através da comunicação; } \\
\text { Adequação a nova forma PCP. }\end{array}$ \\
\hline $\begin{array}{l}\text { Internet } \\
\text { Industrial das } \\
\text { Coisas (IOT) }\end{array}$ & $\begin{array}{l}\text { Sensores, telemóveis que interagem uns } \\
\text { com os outros e cooperam por meio de } \\
\text { componentes inteligentes; } \\
\text { Dispositivos de comunicação e interação } \\
\text { com controladores centrais, conforme a } \\
\text { necessidade; } \\
\text { Descentralização da análise e tomada de } \\
\text { decisão; } \\
\text { Processo de produção semi automatizado e } \\
\text { descentralizado. }\end{array}$ & $\begin{array}{l}\text { Utilização de sensores inteligentes e acessíveis instalados nos } \\
\text { processos de fabricação; } \\
\text { Os produtos são identificados por códigos de radiofrequência, } \\
\text { e as estações de trabalho devem ser realizadas para cada } \\
\text { produto e podem ser adaptados para operação específica. }\end{array}$ \\
\hline
\end{tabular}




\begin{tabular}{|l|l|l|}
\hline Segurança & $\begin{array}{l}\text { Processos baseados em computadores, } \\
\text { sistemas cibernéticos; } \\
\text { Capacidade de computação e } \\
\text { armazenamento. }\end{array}$ & $\begin{array}{l}\text { Envolvem comunicações mais seguras e confiáveis; } \\
\text { Identidades sofisticadas e de gerenciamento de máquinas e } \\
\text { usuários; } \\
\text { Propicia as melhorias nos processos industriais. }\end{array}$ \\
\hline Nuvem & $\begin{array}{l}\text { Maior compartilhamento de dados entre os } \\
\text { sites e os limites da empresa }\end{array}$ & $\begin{array}{l}\text { Tempos de reação em milissegundos; } \\
\text { Resultados eficientes; } \\
\text { Sistematização dos serviços de dados para produção via } \\
\text { controle de processos } \\
\text { Capacidade de produção em escala. }\end{array}$ \\
\hline $\begin{array}{l}\text { Manufatura } \\
\text { Impressão ema } \\
\text { 3D }\end{array}$ & $\begin{array}{l}\text { Produzir componentes individuais e } \\
\text { personalizados; }\end{array}$ & $\begin{array}{l}\text { Pequenos lotes personalizados; } \\
\text { Impressão 3D. } \\
\text { Impacto menonor no sistema de transporte. }\end{array}$ \\
\hline $\begin{array}{l}\text { Realidade } \\
\text { aumentada }\end{array}$ & $\begin{array}{l}\text { Variedade de serviços, peças capazes de } \\
\text { enviar instruções por dispositivos móveis. }\end{array}$ & $\begin{array}{l}\text { Dados coletados e analisados em tempo; } \\
\text { Status da planta é rastreado e analisado; } \\
\text { Falha de uma máquina, a planta pode reagir e reencaminhar } \\
\text { produtos para outra máquina. }\end{array}$ \\
\hline
\end{tabular}

Fonte: elaboração própria.

\subsection{Tecnologias da indústria 4.0 no Agronegócio do Rio Grande do Sul}

As tecnologias da indústria 4.0 no Rio Grande do Sul ainda estão sendo pauta de discussão pelas Universidades, Institutos Tecnológicos, Centros de Pesquisa, Associações Empresariais, Firmas, em aspectos que se referem a conceitos e aplicação. No Quadro 3, apresentar-se as informações de firmas que adotam essas tecnologias, através da coleta de dados secundários, como reportagens jornalísticas e websites.

Quadro 3: Firmas e Startups da Agroindústria do RS identificadas por adotarem Tecnologias da Indústria 4.0

\begin{tabular}{|c|c|c|c|}
\hline Firmas & Tecnologias da indústria 4.0 & Fonte & $\begin{array}{c}\text { Ano da } \\
\text { informação } \\
\text { consultada }\end{array}$ \\
\hline JOHN DEERE & Internet das coisas & www.marketingparaaindustria.com.br & 2016 \\
\hline STARA & Internet das coisas & www.stara.com.br & 2016 \\
\hline $\begin{array}{l}\text { YARA BRASIL } \\
\text { FERTILIZANTES }\end{array}$ & Big data e realidade aumentada & http://cio.com.br/carreira & 2017 \\
\hline AGCO & Realidade aumentada & http://revistapegn.globo.com & 2017 \\
\hline STHIL & Big data & http://www.brasilalemanhanews.com.br & 2017 \\
\hline AEGRO & $\begin{array}{lcc}\text { Software que auxilia } & \text { o } \\
\text { gerenciamento da propriedade } & \end{array}$ & www.correiodopovo.com.br & 2015 \\
\hline ARPAC & $\begin{array}{l}\text { Aeronaves remotamente pilotadas } \\
\text { ou drones de grande porte } \\
\text { destinados a pulverização }\end{array}$ & www.jcrs.uol.com.br & 2017 \\
\hline
\end{tabular}

Fonte: elaboração própria.

A partir do Quadro 3 foram buscadas referências com base nos websites e apresentados como exemplos de firmas do agronegócio que já adotaram ou estão em processo de adoção das tecnologias da indústria 4.0.

A JHON DEERE apresenta uma solução de monitoramento remoto de operações a partir da conexão via internet, através do acesso de informações por meio de laptops, tablets e smartphones. A adoção tecnológica tem a origem na capacidade de coletar, enviar e processar informações, possibilitando o melhoramento da disponibilidade ao desempenho e aos custos de produção da máquina (MARKETING INDUSTRIAL, 2016).

Em relação à STARA, esta firma adotou uma tecnologia mundial inédita, a Telemetria Plataforma conectável, com informações disponíveis em tempo real, conectadas com sistema de gestão da 
propriedade. Isso possibilita o monitoramento em tempo real de qualquer dispositivo móvel, estabelecendo uma operação mais segura e eficiente. O lançamento ocorreu na Agrishow, em 2016, e a tecnologia foi desenvolvida em parceria com a equipe interna de P\&D, colaboradores da SAP Labs Latin America - São Leopoldo e estudantes da área técnica e científica. (STARA, 2016).

A firma YARA BRASIL FERTILIZANTES tem como foco a digitalização dos negócios, atuando de forma vertical. Este método atende, de certa forma, as exigências do novo cenário com o desenvolvimento de soluções digitais criativas e inovadoras e, em alguns casos, pioneiras na área de atuação. A Yara ganhou na categoria agronegócio o prêmio da 17ª Edição do prêmio IT Leaders 2017 que revela o aumento considerável de projetos inovadores voltados para a digitalização dos negócios, com foco na melhoria do nível de satisfação dos clientes externos (CIO, 2017).

A firma AGCO, criada pela Google utiliza como teste o Glass, óculos de realidade aumentada, conectados por tablets para acessar as plataformas. O objetivo é a utilização da tecnologia na linha de montagem dos monoblocos, espécie de chassi dos tratores, os óculos realizam a leitura do código de especificação e identifica o produto. Foi adotado incialmente nos Estados Unidos, no Brasil ainda está em teste de expansão pela própria firma desde 2015 (REVISTA PEQUENAS EMPRESAS, GRANDES NEGÓCIOS, 2017).

Em relação à STHIL, foi lançado em 2017 um novo centro de $\mathrm{P} \& \mathrm{D}$, seguindo o modelo padrão da matriz na Alemanha, por meio de salas individuais para testes, espaço para preparação de motores e áreas administrativas. As tecnologias adotadas são pautadas na digitalização, otimização e automatização dos processos fabris, como mencionado na fonte da pesquisa. A previsão para conclusão do centro de P\&D, é no final de 2018 (BRASILALEMANHANEWS, 2017).

A AEGRO, foi fundada em 2015, e está presente em nove propriedades rurais, produtoras de arroz, localizadas na Fronteira-Oeste do Rio Grande do Sul. A ideia futura é expandir para outras lavouras de grãos, com a intenção de melhorar os processos produtivos, financeiros e comerciais. Este aplicativo pode ser utilizado de celulares, tablets, proporcionando informações oportunas e precisas, melhorando assim o preparo do solo, gestão do processo, utilização de defensivos. Este cenário está adequado ao 'Big Data', tecnologia pertencente à Indústria 4.0 (CORREIO DO POVO, 2015).

A ARPAC é uma startup incubada pela Unitec do Tecnosinos de São Leopoldo que desenvolve aeronaves remotamente pilotadas ou drones de grande porte destinados à pulverização agrícola, tanto de defensivos como para semeadura. Como vantagens, aponta a economia de tratar doenças e pragas da lavoura, sendo necessário o auxílio do piloto em áreas perigosas e agilidade na aplicação (JORNAL DO COMÉRCIO RS, 2017).

Pode-se constatar a presença de firmas que adotam as tecnologias em estudo no RS, sejam essas multinacionais ou empresas familiares. No próximo capítulo, é apresentado o método de pesquisa utilizado.

\section{Procedimentos Metodológicos}

Considerando os objetivos do presente trabalho, adotou-se a pesquisa exploratória para avançar nos objetivos do trabalho, amparado nas orientações de Hair Jr. et al, (2005). Em relação à abordagem do problema, trata-se de uma pesquisa qualitativa, como descrito por Marconi e Lakatos (2010). Em relação a estratégia ou procedimento técnico, trata-se de um estudo de multi casos, seguindo a lógica de Triviños (2010) e Yin (2010).

\subsection{Sujeitos da pesquisa e coleta de dados}

Para a investigação dos sujeitos da pesquisa foram consideradas as firmas, como objeto central do estudo e outros atores como: especialistas da indústria 4.0; especialistas do agronegócio; universidades; startups e instituições. A pesquisa procurou em analisar a adoção de inovações pela firma através do processo sistêmico, que depende de diferentes atores de um Sistema de Inovação.

A técnica descrita é denominada cientificamente de snowball sampling, ou seja, 'bola de neve', principalmente para identificação de especialistas e instituições. Na ótica de Biernacki e Waldorf (1981, p. 141), trata-se de uma técnica adequada para a investigação de uma pesquisa a respeito de um assunto 
pouco explorado, e que exige a identificação das pessoas pertencentes a um determinado grupo social para localizar pessoas ou outros atores para o estudo. O método de amostragem é usado quando os entrevistados iniciais ajudam a encontrar outros convidados potenciais em contribuir com o estudo. Por meio desta característica, a amostra é definida no decorrer do estudo e não apresenta um tamanho definido (GOODMAN, 1961).

Nesse sentido, a partir da amostragem snowball sampling, para o presente estudo foram selecionados os seguintes entrevistados:

a) Firmas: 3 dirigentes de firmas do agronegócio;

b) Especialistas do agronegócio: 3 especialistas;

c) Especialistas em tecnologia da indústria 4.0: 2 especialistas;

d) Universidades: 1 coordenador de curso de engenharia agronômica;

e) Startups: 1 empreendedores de startups;

f) Instituições: 1 instituição de serviços para micro e pequenas empresas; 1 instituição de pesquisa agropecuária;

g) Órgãos Públicos: Ministério da Ciência, Tecnologia, Inovações e Comunicações (MCTIC); Ministério da Indústria, Comércio Exterior e Serviços (MDIC).

As entrevistas foram realizadas por videoconferências, com exceção das entrevistas com a Instituição A e o Especialista $\mathrm{C}$, que foram realizadas pessoalmente.

\subsection{Técnica de coleta e análise de dados}

A entrevista semiestruturada oportuniza ao entrevistado a possibilidade de apresentar suas experiências, decorrente do foco principal determinado pelo pesquisador. Nesta lógica, esta técnica permite respostas livres e espontâneas do entrevistado e valoriza a atuação do entrevistador (HAIR Jr et al, 2005; TRIVINOS, 2010, LAKATOS, MARCONI, 2010).

Foram realizadas 14 entrevistas entre os dias 20 de agosto de 2017 até 15 de outubro de 2017, estimando um tempo de 30 a 60 minutos cada entrevista. Visando manter a ética e a integridade da amostra, os entrevistados são identificados por códigos alfabéticos atribuídos como Firmas (A, B, C e D); Instituições (A, B, C, MCTIC e MDIC); Especialistas (A, B, C, D e E), conforme determinado por Bardin (2009). As categorias de análise foram extraídas do Quadro 1, conforme revisão da literatura.

Em relação a análise e interpretação dos dados, no presente estudo, utilizou-se a análise do conteúdo, seguindo as orientações de Bardin (2009, p. 121): 1) pré- análise; 2) a exploração do material; e 3) o tratamento dos resultados: a inferência e a interpretação. Em síntese, o Quadro 4 apresenta, em ordem cronológica, a lista dos investigados para o estudo, data e duração da entrevista.

Quadro 4 - Informações das entrevistas realizadas

\begin{tabular}{|l|l|l|l|l|l|}
\hline Amostras & Entrevistado & Caracterização da amostra & $\begin{array}{l}\text { Data da } \\
\text { entrevista }\end{array}$ & $\begin{array}{l}\text { Duração da } \\
\text { entrevista }\end{array}$ & $\begin{array}{l}\text { Técnica de realização } \\
\text { da entrevista }\end{array}$ \\
\hline \multirow{4}{*}{ Firmas } & Firma A & Firma Startup & $16 / 10 / 2017$ & $34: 35$ & Gravada \\
\cline { 2 - 6 } & Firma B & Firma do agronegócio & $17 / 10 / 2017$ & $54: 45$ & Telefone \\
\cline { 2 - 6 } & Firma C & Firma do agronegócio & $13 / 09 / 2017$ & $42: 38$ & Gravada \\
\cline { 2 - 6 } & Firma D & Firma do agronegócio & $19 / 10 / 2017$ & $36: 21$ & Gravada \\
\hline \multirow{5}{*}{ Instituições } & Instituição A & Assessoria & $09 / 10 / 2017$ & $48: 31$ & Gravada \\
\cline { 2 - 6 } & Instituição B & Instituto Tecnológico & $22 / 08 / 2017$ & $48: 23$ & Gravada \\
\cline { 2 - 6 } & Instituição C & Universidade & $28 / 09 / 2017$ & $1: 01: 06$ & Gravada \\
\cline { 2 - 6 } & MCTIC & Ministério MCTIC & $08 / 11 / 2017$ & $20: 25$ & Gravada \\
\cline { 2 - 6 } & MDIC & Ministério MDIC & $21 / 11 / 2017$ & $25: 20$ & Telefone \\
& $\begin{array}{l}\text { Especialista } \\
\text { A }\end{array}$ & $\begin{array}{l}\text { Especialista em tecnologia } \\
\text { da indústria 4.0 }\end{array}$ & $24 / 08 / 2017$ & $57: 26$ & Gravada \\
\cline { 2 - 6 } & $\begin{array}{l}\text { Especialista } \\
\text { B }\end{array}$ & $\begin{array}{l}\text { Especialista em tecnologia } \\
\text { da indústria 4.0 }\end{array}$ & $23 / 08 / 2017$ & $57: 26$ & Gravada \\
\cline { 2 - 6 } & $\begin{array}{l}\text { Especialista } \\
\text { C }\end{array}$ & $\begin{array}{l}\text { Especialista em Inovação do } \\
\text { Agronegócio }\end{array}$ & $01 / 09 / 2017$ & $50: 43$ & Gravada \\
\cline { 2 - 6 } & $\begin{array}{l}\text { Especialista } \\
\text { D }\end{array}$ & $\begin{array}{l}\text { Especialista em Inovação do } \\
\text { Agronegócio }\end{array}$ & $02 / 09 / 2017$ & $01: 03: 49$ & Gravada \\
\cline { 2 - 6 } & Especialista & Especialista em Inovação do & $09 / 09 / 2017$ & $28: 07$ & Gravada \\
\hline
\end{tabular}


Fonte: elaboração própria.

\section{Análise dos Resultados}

No conjunto das nove tecnologias da indústria 4.0, como destacado na revisão da literatura, aquelas adotadas pelas firmas investigadas foram: Internet das Coisas - IOT, Big Data e Robótica. Portanto, a análise e conclusão do estudo são referentes a esse conjunto de tecnologias, conforme apresentado no Quadro 5.

Quadro 5: Firmas e startup do agronegócio investigadas por adotarem Tecnologias da Indústria 4.0

\begin{tabular}{|l|l|l|l|l|l|}
\hline Firmas & $\begin{array}{l}\text { No de } \\
\text { colaboradores } \\
\text { no Brasil }\end{array}$ & $\begin{array}{l}\text { Localização } \\
\text { geográfica no RS }\end{array}$ & $\begin{array}{l}\text { Ano de } \\
\text { fundação }\end{array}$ & $\begin{array}{l}\text { Principais produtos } \\
\text { fabricados }\end{array}$ & Principais inovações \\
\hline A & 6 & São Leopoldo & 2014 & $\begin{array}{l}\text { Drones de pulverização } \\
\text { agrícola; } \\
\text { Aeronaves remotamente } \\
\text { pilotadas. }\end{array}$ & Robótica \\
\hline B & 1000 & Montenegro & 1837 & $\begin{array}{l}\text { Hardware com conecção de } \\
\text { um servidor da Firma B via } \\
\text { internet. }\end{array}$ & Internet das coisas \\
\hline C & 2100 & Não me Toque & 1960 & $\begin{array}{l}\text { Máquinas agrícolas } \\
\text { conectadas por telemetria. }\end{array}$ & Internet das coisas \\
\hline D & 6.000 & $\begin{array}{l}\text { Porto Alegre. 30 } \\
\text { unidades em todo } \\
\text { o Brasil }\end{array}$ & 1913 & $\begin{array}{l}\text { Playground - uma aplicação } \\
\text { de Big Data para toda a cadeia } \\
\text { produtiva; } \\
\text { Drone com uma câmara 3D, } \\
\text { por meio de IOT. }\end{array}$ & $\begin{array}{l}\text { Internet das coisas e } \\
\text { Big Data }\end{array}$ \\
\hline
\end{tabular}

Fonte: elaboração própria.

A decisão de adotar tecnologias, entre as firmas investigadas A, B e D, ocorre, por meio da integração do conhecimento por parte da cultura inovadora da firma, através do intercâmbio com multinacionais, que oportunizou conhecer a tecnologia e adaptar à realidade econômica do Brasil. Notouse uma particularidade na firma $\mathrm{C}$, que é de origem familiar, que foi a utilização de seu centro de $\mathrm{P} \& \mathrm{D}$ para gerar atividades inovativas, com formação de equipes interdisciplinares, testes de protótipos, conectividade, informações em tempo real, permitindo maior competitividade nacional e mundial.

Sendo assim, as firmas investigadas apontaram que a decisão de adotar tecnologias da indústria 4.0 são pautadas pela inovação disruptiva de seus processos, por meio da identificação de ganhos econômicos para o setor do agronegócio. Constatou-se ainda, que as firmas, A, B e C são caracterizadas por estarem localizadas antes da porteira, e atuam como "puxadoras" de tecnologias (technology-push), o que estimula as firmas dentro e pós porteira a repensarem as vantagens que a adoção de tecnologias da indústria 4.0 poderão provocar em seus negócios.

De forma mais específica, destaca-se que a Firma A realiza a integração de drone com robótica, oportunizando vantagens para o produtor rural. A Firma B ressalta a escolha de um hardaware que auxilia o gerenciamento da propriedade rural por meio da IOT, analisando desde o solo até a assistência técnica. A Firma C mostrou-se preparada para escolher a internet das coisas como a tecnologia 4.0 que oferece uma estratégia de gestão, por meio da conectividade em tempo real. A Firma D trabalha com tecnologias Big Date e Internet das coisas.

Pode-se constatar que as firmas A, B, e C escolheram as tecnologias para auxiliar as propriedades rurais, com o desafio de tornar a tecnologia a um preço acessível por meio de estratégias cooperativas, aumento na produtividade, conectividade, monitoramento em tempo real, ferramentas que auxiliam na tomada de decisão do produtor rural. A Firma D escolheu essas tecnologias para melhoria dos processos internos e a aplicabilidade para os demais elos da cadeia, estão em fase conceitual.

No que se refere a tendência, as firmas apontaram semelhança com relação a busca do conhecimento internacional para adotar as tecnologias em estudo. Esse intercâmbio oportuniza identificar 
os avanços que a prática e ciência determinam. Tem-se observado que ao adotar, as firmas buscam conhecimento com outros países e posteriormente adaptam a realidade do Brasil, bem como a criação de parcerias para inovar e eliminar barreiras e incertezas quanto a decisão de adotar tecnologia em estudo. Destaca-se ainda como tendência o aumento de produtividade, ou seja, produzir mais, com a mesma área destinada a plantação, por meio do incremento de novas funções da tecnologia existente.

Também, considera-se importante a adoção de tecnologias da indústria 4.0, como forma de promover a qualidade de vida da população, otimização da força de trabalho oportunizando a ampliação da capacidade de diversificação. Cabe mencionar que a tendência é a transformação das firmas do agronegócio em recursos ociosos, em que incide a possibilidade de observar novas alternativas de crescimento.

No que se refere às características da adoção, entre as investigadas foram: integração de hardware e software; conectividade; soluções inteligentes na tomada de decisão; interação com clientes e fornecedores; conversação entre processos; qualificação da mão de obra; pesquisa \& desenvolvimento. A transformação ocorrida no setor de máquinas e equipamentos agrícolas, apresenta um perfil inovador desde os anos 2000, quando surgiu a agricultura embarcada e agricultura de precisão como mencionada pela Firma C, por meio das falhas de integração entre usuários e máquinas dos produtos importados, fez a mesma, buscar conhecimento para entender e a repensar melhor a adoção dessas tecnologias.

No caso da Firma D, a adoção ocorreu por meio de parcerias. A firma adotante realiza teste de protótipos, workshops, planejamento, interdisciplinaridade para alcançar o objetivo final: "As interações vão desde o surgimento das falhas iniciais, através da elaboração de workshops para discutir essas tecnologias, realização de visitas nas unidades para enxergar o caso de uso real, reuniões, para discutir melhorias da tecnologia, até cenários que co-criação" (FIRMA D).

As principais dificuldades externas, citadas entre as investigadas, é o acesso ao crédito, burocracia em termos de políticas públicas e participação de projetos conectividade, banco de dados estatísticos em tecnologia do setor, educação, cultura empreendedora, imaturidade da firma, parceiros para auxiliar no processo de adoção. Como dificuldades internas, as firmas mencionam a produtividade, as relações de trabalho, normas internas da firma, segurança e proteção do ser humano por interagir com a robótica nas rotinas organizacionais, acesso ao crédito via repasse do BNDES e BRDE, burocracia e o ambiente educacional que impede a cultura do empreendedorismo.

Por outro lado, conforme investigação, houve firmas que não encontraram dificuldades, devido à sua cultura inovadora, porém, mencionam que por causa das políticas públicas burocráticas, apresentam dificuldade de interpretação e informações desconectadas e subjetivas como, também, ausência de dados estatísticos do setor sobre indicadores de tecnologia e eficiência produtiva.

Em relação à mão de obra, a busca por conhecimento é necessária no processo de adoção da firma. Por meio da inovação incremental ou mesmo disruptiva, se faz necessário a qualificação da mão de obra, reorganização da capacidade da firma, bem como a requalificação dos colaboradores, pelo fato de operacionalizar processos e produtos em conjunto com robôs, sensores, alimentando informações em nuvem, gerando testes através da realidade aumentada, são alguns exemplos do desafio da empregabilidade no cenário das tecnologias 4.0.

Entre as respondentes, a utilização da mão de obra foi por meio de: interação internacional, participação do gestor de alto escalão, equipe interna no centro de $\mathrm{P} \& \mathrm{D}$, consultores e técnicos no auxílio dos testes e aplicações da tecnologia 4.0, o que proporcionou aprendizados e autonomia para a consolidação das tecnologias em estudo no Brasil. Convém salientar que as Firmas C e D institucionalizaram a adoção da inovação de acordo com seu nicho de mercado, promovendo a geração de ideias no ambiente interno em conjunto com a equipe interdisciplinar, com foco no processo e com o objetivo de operacionalização segura e confiável para seus clientes

As experiências entre as investigadas divergem quanto ao auxílio do Estado frente a adoção de tecnologia da indústria 4.0. Quanto as Firmas A e B, afirmam não ter acesso e não ter utilizado as linhas de crédito. Quanto as Firmas C e D, utilizaram a Lei do Bem e a Finep, as quais apontaram este aporte financeiro necessário para acelerar a adoção de tecnologia, isso justifica-se o fato das mesmas, em possuir regras simples de gastos em P\&D e simplifica a aplicação da racionalidade limitada, o que gera uma ociosidade existente entre as rotinas organizacionais. 
Destaca-se também o papel das firmas multinacionais, como a busca de recursos no exterior para gerenciar o processo de adoção, devido a financiamento por meio de recursos próprios por parte da firma. As firmas B e D, mencionam a parceria público-privado em projetos de ciência e tecnologia e educação, as quais buscam crescimento em produtividade de máquinas e equipamentos, eficiência nos fatores de produção e na gestão, tornando-se competitiva nacionalmente e internacionalmente, através do patenteamento de produtos e marcas o que facilita a adoção da inovação.

Nas firmas do agronegócio, constata-se uma interação de diversos atores, por meio de consultorias, as quais trabalham no foco de seminários, workshop e projetos que visam o fortalecimento do empreendimento na busca e seleção de rotinas dinâmicas e de investimento. Nota-se que existe uma relação de aprendizado da firma com o contexto institucional por estratégias ou organização interna da firma. As universidades representam conhecimentos variados e, também, a formação de recursos humanos qualificados, as agências governamentais e instituições de pesquisa impõem o acúmulo de competências nas firmas por meio suporte às atividades de pesquisa, enquanto as instituições financeiras trabalham com os possíveis riscos inerentes às atividades inovadoras.

Quanto aos resultados, as firmas apresentaram crescimento em seu faturamento, além da otimização da força de trabalho. Considera-se a importância da indústria antes da porteira como impulsionadora da tecnologia para dentro da mesma, buscando atender pequenos, médios e grandes proprietários rurais. Ressalta-se também a cooperação para ampliar o número de adotantes dentro da porteira, devido ao capital ser incompatível com a aquisição individual de cada tecnologia.

Quanto aos resultados de inovação, foram analisados os testes de protótipos, que são necessários para que a eficiência tecnológica seja capaz de transformar itens manufaturados em produtos de alto valor agregado, para o aumento da produtividade de alimentos, redução dos custos de produção, controle para a tomada de decisão, informações precisas e oportunas, aumentando, assim, a rentabilidade em todos os elos da cadeia.

\subsection{Percepção dos atores institucionais da adoção tecnológica pelas firmas}

Os atores institucionais envolvidos no estudo, são assessoria, instituto tecnológico, universidade, MCTIC e MDIC.

Com base nos atores investigados A, B e C, a escolha das tecnologias da indústria 4.0, altera os padrões da capacidade interna da firma - nos setores de finanças, marketing, produção e recursos humanos -, proporcionando oportunidades adequadas às necessidades dos clientes, automação de processos e conversação entre os mesmos, identificando quais os valores para o mercado, para que o consumidor produza seus próprios conteúdos, com customização de matéria prima, preço e garantia de recursos naturais.

As instituições apontaram que as dificuldades neste processo de adoção são: a indústria defasada em termos de infra estrutura; internet limitada; cultura resistente dos proprietários rurais em adotar inovações; ausência de conhecimento sobre tecnologias da indústria 4.0 em todos os elos da cadeia do agronegócio.

No que se refere as tendências, os investigados A, B e C apontam que irão contribuir para o desenvolvimento industrial, através do aumento da produtividade, novas funções de trabalho intelectual, maior proximidade entre firmas e Universidades e Centros de Pesquisa nacionais e estrangeiros, interdisciplinaridade na mão de obra da firma, preço acessível ao consumidor final, identificação das tecnologias que deverão adaptar-se no ambiente da firma, eficiência em capacidade produtiva, comparação de vantagens entre as tecnologias da indústria 4.0 com as tecnologias já existentes, tornandose positivas em termos econômicos, sociais e ambientais.

Cabe mencionar ainda, que visões de diferentes instituições integram o desenvolvimento da firma e suas capacidades, por meio de parcerias com atores externos para qualificação, identificando os gargalos das firmas brasileiras antes da porteira. Em complemento, identifica-se o trabalho cultural apresentando os benefícios que a tecnologias poderão oportunizar para este conjunto de firmas. Quanto ao pós-porteira, não ocorreram observações. 
Nota-se ainda que as características para os investigados A, B e C indicam a conexão entre equipamentos, auxílio na tomada de decisões do produtor, interação com as atividades dentro da porteira, interação entre humanos e robôs, interação colaborativa, inserção das firmas nas cadeias globais e interdisciplinaridade do conhecimento. Em relação à mão de obra, os investigados $\mathrm{A}, \mathrm{B}$ e C destacam esforços inovativos através da relação Universidade-Empresa, no desenvolvimento de novas metodologias de qualificação profissional; os Institutos Tecnológicos no desenvolvimento de protótipos, máquinas e equipamentos; as empresas de consultorias na reorganização interna dos processos e funções da firma; os especialistas no desenvolvimento de workshops e discussões com cadeia do agronegócio sobre a temática.

Para os investigados A, B e C, há uma convergência por parte do papel dos atores externos, através da movimentação dos sindicatos, os institutos tecnológicos de pesquisa e o intercâmbio de Universidades, as quais estão mobilizando-se por meio de interação no exterior, para posteriormente aplicar as tecnologias da indústria 4.0, de acordo com a realidade das firmas Brasil.

Em relação aos resultados, os atores entrevistados apontam que as firmas antes da porteira possuem o papel de impulsionador da tecnologia da indústria 4.0 por meio de máquinas, implementos, insumos, sementes, matéria prima, pós-venda e suporte, o que proporciona uma melhoria de processos pelo fato de oportunizar melhores resultados e com esforço físico customizado. Dentro da porteira, o papel dos atores externos é fundamental para disseminar a informação e apresentar as oportunidades de ganhos em produção e financeiros. Destaca-se o papel dos atores como intermédio entre as parcerias público-privado para contribuir através de incentivos e financiamento, para a qualificação dos produtores rurais em operacionalizar as tecnologias da indústria 4.0, o que de certa forma, reflete em eficiência em custos, ganhos em qualidade, segurança no escoamento da produção, aumentando o volume de commodities em um mesmo espaço produtivo.

No pós-porteira, faz-se necessário, trabalhar para explorar a manufatura em componentes de alto valor agregado, por meio de competências intelectuais e técnicas, em conjunto com máquinas e equipamentos de fronteira tecnológica, desenvolvida pelas firmas antes da porteira. Isso porque, neste elo da cadeia produtiva, a percepção sobre o benefício da adoção das tecnologias em estudo ocorrerá de maneira gradativa, se comparado com os demais elos da cadeia (antes da porteira e dentro da porteira). Outro elemento importante a ser explorado, é a noção de valor por parte do consumidor final, quanto à aquisição de produtos e serviços originários da indústria 4.0.

Participaram da amostra os Ministérios da Ciência e Tecnologia e Inovação (MCTI) e o Ministério da Indústria e Comércio Exterior (MDIC), ambos destacam o desenvolvimento do Plano Nacional de Manufatura Aditiva Avançada e o Plano Nacional de Internet das coisas. Estes estudos, foram desenvolvidos a nível nacional, em uma estratégia que envolveu Especialistas, Institutos de Pesquisa, Universidades e Firmas, em uma tentativa de identificar oportunidades no Brasil em todas as atividades econômicas.

Conforme informações obtidas no Plano Nacional de Manufatura avançada, este plano possui a tendência de criar estratégias de estímulo para a modernização fabril através da robótica, informática, internet das coisas, nanotecnologia nos processos produtivos. O Plano de Internet das Coisas (Internet of Things - IOT) busca acelerar a implantação desta tecnologia como instrumento de desenvolvimento sustentável no Brasil, promovendo o aumento da competitividade da economia, o fortalecimento das cadeias produtivas nacionais e a promoção da melhoria da qualidade de vida humana.

Convém esclarecer que tais planos desenvolvidos apontam ser extensos, devido à diversidade das atividades econômicas e a heterogeneidade das firmas brasileiras. Sua aplicação e efeito prático tornam-se gradativo entre as regiões, o que pode gerar disparidades da adoção de tecnologias em diferentes setores e espaços geográficos. Os ministérios entrevistados apontam dificuldades no processo de elaboração dos planos para que, posteriormente, sejam adotados pelas firmas. Essas dificuldades são oriundas de recursos financeiros e humanos, desemprego, preparação das firmas para adotar as tecnologias em estudo e também, a ausência de políticas públicas eficazes para as micro e pequenas firmas.

A formação destes planos visa reduzir as dificuldades identificadas no estudo, bem como auxiliar a firma em determinar estratégias de condução dos negócios, que as tecnologias da indústria 4.0 
provocarão no desempenho das mesmas. Este plano também oportuniza ações que visem uma capacitação diferenciada por meio da formação e requalificação da mão de obra em processos produtivos.

Conforme o Plano Nacional de IOT, desenvolvido em parceria com o BNDES, participaram 380 especialistas no assunto; 4600 convites para o debate sobre bytes de IOT, 2.200 contribuições na consulta pública. Foram realizadas 100 entrevistas exploratórias e 100 horas de workshops com especialistas. Em relação ao papel do Estado, é de atuar como um incentivador das tecnologias da indústria 4.0, através da conectividade, incentivos humanos, físicos e financeiros, firmar parcerias públicos-privado para otimizar esforços e acelerar o processo.

Conforme obtido nas informações das firmas, instituições e especialistas, para a eficiência e eficácia do processo de adoção de tecnologia, se faz necessário a parceria público-privado. Mostra-se uma parceria entre os ministérios na condução dos planos que comportam a tecnologia da indústria 4.0. Neste sentido, a mobilização dos mesmos fez a integração de especialistas, firmas e instituições, no objetivo de desenvolver competências e conhecer a realidade do Brasil, na tentativa de adotar a manufatura aditiva.

A relação governo e atores externos é necessária para aproximar os dados obtidos no exterior e adaptar à realidade brasileira por meio da pesquisa, extensão, testes de protótipos, técnicas de gestão, melhorias em infraestrutura em termos de energia, conectividade, assistência técnica, suporte tecnológico, como também adaptar as infraestruturas da firma para a adoção das tecnologias em estudo, bem como, a interação do ser humano das rotinas em nível operacional e intelectual.

\subsection{Percepção dos especialistas da adoção tecnológica pelas firmas}

Nesta etapa, foram investigados especialistas em indústria 4.0, com o objetivo de assimilar e compreender a temática e sua importância para firmas e suas perspectivas na dinâmica dos negócios. Os especialistas do agronegócio, com o foco de identificar o conhecimento dos mesmos, sob a ótica da visão acadêmica e institucional que as tecnologias da indústria 4.0.

As percepções de especialistas em indústria 4.0 divergem de acordo com o conhecimento obtido de cada um sobre as tecnologias específicas. É importante destacar que, embora a conceituação científica se encontra em fase inicial, na prática, esta existe há mais de uma década, pois países como a Alemanha analisaram sua economia durante uma série temporal de 10 anos para identificar o comportamento de firmas que adotaram tecnologias avançadas, em comparação com os modelos tradicionais de negócios.

Conforme observação realizada pelos especialistas do agronegócio, através de estudos e levantamentos, a escolha da tecnologia da indústria 4.0, apresentam benefícios para o setor do agronegócio, bem como a firma deve adotar uma nova cultura organizacional, voltada a P\&D, oportunizando maior valor agregado nos produtos finais, ocorrendo a customização de mão de obra, matéria-prima e oferta de produtos a um preço acessível ao consumidor final. Através deste cenário, na percepção dos investigados, é que gradativamente, a disseminação entre todos os elos da cadeia torna-se essenciais, favoráveis a adoção, tornando assim, o setor competitivo com outras economias de fronteira tecnológica.

Por outro lado, entre a visão dos especialistas A, B, C, D e E observa-se também uma preocupação em relação à adoção destas tecnologias, já que o Brasil é uma economia em desenvolvimento e apresenta gargalos em termos de inovação tecnológica e base educacional, instabilidade macroeconômicas, lentidão por parte do Estado em promover ações pró ativas, favoráveis ao processo de adoção, conectividade, cultura organizacional, mão de obra qualificada, infraestrutura tecnológica, pouca discussão entre os elos da cadeia produtiva quanto a temática.. O investigado A menciona "precisa haver maior interação entre os atores instituicionais e as firmas para, num momento incial, conhecer a real situação da firma, para posteriormente, definir qual estratégia a ser adotada para a inserção na indústria 4.0".

Os investigados D e E apontam um complexo de dificuldades educacionais, tecnológicos, infraestrutura e de aprendizagem organizacional que o setor enfrenta e limita o processo de adoção por parte da firma. Investir em tecnologia, na visão do investigado E, é necessário para estimar o custo de oportunidade do investimento em tecnologia, devido as dificuldades mencionadas. Constata-se no estudo que as dificuldades estão concentradas no papel do Estado em organizar de forma sistêmica o acesso às tecnologias e oportunizar condições que favoreçam a confiança das firmas do setor para investir em tecnologia e competir com economias desenvolvidas. 
Em relação às tendências, a opinião dos especialistas diverge quanto à adoção de tecnologias. Os investigados B e E mantêm sua opinião otimista, já os especialistas $\mathrm{C}$ e $\mathrm{D}$ identificam um cenário pouco favorável para o desenvolvimento de tecnologias da indústria 4.0 no setor do agronegócio brasileiro. Sendo assim, os especialistas apontaram: a alteração nos modelos de negócios, o enxugamento das firmas, a produção em lotes personalizados, a reorganização das plantas produtivas, a agregação de valor ao produto final, a maior competitividade nas exportações, a redução de custos, a redução da mão de obra e a utilização via dispositivos de fácil acesso como smartphones, foram fatores mencionados pelos investigados B e D. Sua adoção ocorre por meio de indústrias antes da porteira, que beneficiarão, de forma gradativa, as firmas dentro e pós-porteira, tal qual apresentado pelo investigado $\mathrm{E}$, em que os primeiros adotantes terão maiores ganhos em relação a concorrência.

Neste sentido, pode-se atribuir que as tecnologias em estudo impactarão de forma positiva em toda a cadeia, proporcionando uma mudança no aprendizado e conhecimento da mão de obra e na interação ser humano e robôs no ambiente de trabalho. $\mathrm{O}$ investigado $\mathrm{C}$ "a força de trabalho deve ser utilizada por robôs, enquanto o ser humano precisará de conhecimento intelectual para operacionalizar os sistemas inteligentes". Aposta-se na visão dos especialistas B e E como um grande avanço para o desenvolvimento social e econômico por meio de um caráter evolutivo no aumento da produtividade e um novo modelo mental da firma.

Quanto à tendência negativa, os investigados C e D mencionam que a firma brasileira e, em específico, a do Rio Grande do Sul, não estão atuando na fronteira tecnológica. O que caracteriza esse atraso é a falta de interesse do produtor, firmas em investir em tecnologia e a baixa conectividade de internet. As diferenças obtidas entre os especialistas investigados, nota-se as realidades vivenciadas individualmente, muito refere-se ao setor do agronegócio ser heterogêneo em cada região do Estado do Rio Grande do Sul e, também, do Brasil. Percebe-se, ainda, a disparidade do setor em aspectos relacionados à adoção, sendo um possível entrave para a disseminação da adoção em todos os elos da cadeia.

Constatou-se uma convergência de ideias entre os especialistas, A, B, C, D e E, bem como, à reorganização dos setores internos da firma, comunicação entre processos, aumento da capacidade intelectual do colaborador, conexão entre máquinas e humanos, aumento da produtividade com o mesmo espaço em produção, redução de custos.

Com base nas características apresentadas pela amostra, percebeu-se que o impacto ocorre no ambiente interno e externo da firma e em todos os elementos que constituem o processo produtivo. Aponta-se um cenário favorável para a geração de novos negócios, proporcionados pelo conhecimento científico e prático, que determina a competitividade da firma.

No que se refere à mão de obra, há uma divergência entre os especialistas investigados. De um lado, os especialistas A, C e D apontam que a qualificação ocorre com o intercâmbio de conhecimento com firmas multinacionais em que há uma mobilização dos países desenvolvidos através de startups, institutos de pesquisa e centros de P\&D. Destaca-se também o papel da Universidade e Institutos Tecnológicos para a formação e a requalificação da mão de obra.

Percebe-se, ainda, que a partir da visão do Especialista $\mathrm{D}$, cabe às multinacionais serem pioneiras no processo de adoção de tecnologia e desenvolvimento de mão de obra no Brasil. Isto justifica-se pelo fato da carência na estrutura educacional de base e tecnológica, ambientes empresariais que oportunizem a aplicação do conhecimento adquirido em firmas de fronteira tecnológica de origem brasileira, salvo a exceção, de firmas detentoras de uma cultura inovadora. Considera-se também, a heterogeneidade do setor, comprometendo a adoção de tecnologias em todos os elos da cadeia.

Já os investigados B e E mencionam que as tecnologias da indústria 4.0 apontam para um novo modelo de negócios e novas profissões. Porém, a baixa qualificação da mão de obra do Brasil será um desafio para transformar o trabalho operacional em trabalho intelectual no exercício das atividades que envolve tecnologias da indústria 4.0.

A exigência da mão de obra qualificada torna-se um diferencial no processo de adoção das tecnologias em estudo por meio da institucionalização das firmas através da $\mathrm{P} \& \mathrm{D}$, de produtos e processos com base em seus segmentos. Sendo assim, nota-se que a firma, quando for de grande porte, investe recursos próprios em adoção de tecnologia, o que torna a própria mão de obra com maior 
qualificação, enquanto as firmas pequenas depende de estratégias de cooperação e parcerias para esta finalidade.

Em relação ao papel do Estado, os investigados, B, C, D e E apontam falhas na política de inovação em promover a adoção de recursos tecnológicos nas firmas do agronegócio. Os mesmos constataram que serão necessárias parcerias público-privados - assistência técnica, educacional, tecnológica -, linhas de crédito específicas para a adoção de tecnologias da indústria 4.0 e para a aquisição de tecnologias no agronegócio, o repasse de crédito via BNDES e BRDE, envolvendo o ambiente das firmas em editais de fomento a P\&D.

$\mathrm{O}$ investigado $\mathrm{E}$ menciona que nas economias desenvolvidas, o Estado atua como indutor para o processo de adoção de tecnologia na firma. A realidade do Brasil compromete a incerteza, pois não há garantia de financiamento a longo prazo, como forma de incentivar a inovação, por meio de estratégias sustentáveis.

Através das parcerias público-privado, em que os atores externos assumem a importância de fomentar o processo de adoção das firmas, destacam-se as Universidades, Centros de Pesquisa, Institutos tecnológicos, consultorias, projetos governamentais, entidades de classe, sindicatos, entre outros atores que promovam e qualificam a firma, em termos qualitativos e quantitativos.

Os resultados sob a ótica dos investigados apontam que será um processo lento, com várias limitações e dificuldades, porém, torna-se um potencial para o Brasil desenvolver produtos que possam ser competitivos internacionalmente. As tendências observadas em feiras nacionais e multinacionais, associadas ao conhecimento científico e técnico com relação as firmas multinacionais e universidades e centros de pesquisa, e institutos tecnológicos. Ainda mencionam as tecnologias como sensores, robôs, internet das coisas, como promissoras para a firma, oportunizando inovação nos processos via tecnologia da indústria 4.0. Além de proporcionar as melhorias na capacidade produtiva, e na qualidade de vida da sociedade, por meio da comunicação entre processos, garantindo a disseminação da tecnologia em todos os elos da cadeia.

\section{Considerações Finais}

O estudo teve como objetivo compreender o processo de adoção de tecnologias da indústria 4.0 por firmas do agronegócio do Rio Grande do Sul. Constatou-se que três firmas - das quatro investigadas - que estão adotando tecnologias da indústria 4.0 são multinacionais. Também foi revelado que a firma C é de origem familiar e que, através da utilização do próprio centro de $\mathrm{P} \& \mathrm{D}$, apontou que é possível adotar uma tecnologia de fronteira. Destacam-se que tecnologias da Indústria 4.0 adotadas pelas firmas investigadas são: robótica, internet das coisas e big data.

No que se refere às características das firmas que estão adotando as tecnologias da indústria 4.0, constatou-se no Rio Grande do Sul o importante papel das multinacionais (antes da porteira). Cabe destacar que a participação da firma nas atividades de treinamento e desenvolvimento de gestores, líderes de equipe e outros os colaboradores, como forma de reduzir incertezas diante da adoção de tecnologias da indústria 4.0.

Dentre os atores do sistema de inovação que participam deste processo, destacam-se as universidades e instituições de ensino, para a qualificação de recursos humanos, tecnológicos e sociais, que atuam na preparação dos jovens profissionais focados nas tecnologias em estudo e a requalificação dos profissionais já atuantes. O papel dos institutos de pesquisa e tecnologia, no desenvolvimento e testes de protótipos, máquinas e equipamentos, como também, as consultorias, que auxiliam as firmas no processo de gestão e preparação para operacionalização das tecnologias em estudo, por meio de seminários e projetos em parceria público-privado. Cabe mencionar ainda, que entre as investigadas, afirmam há pouca participação de sindicatos, entidades de classe e agentes políticos como forma de interação e discussão das tecnologias abordadas no estudo.

Participam também, como atores do Sistema Nacional de Inovação (SNI), os órgãos públicos, na condução de políticas públicas, como apontado pelas investigadas $\mathrm{C}$ e $\mathrm{D}$, a Lei do Bem e a Finep, que atuam como mecanismos para estimular o setor privado em investir em tecnologia. Por outro lado, as firmas $\mathrm{A}$ e $\mathrm{B}$ apontam não ter acesso às informações, ocorrendo o investimento com recursos próprios no que se refere a adoção tecnológica. Vale ressaltar, a participação do MCTIC e MDIC no desenvolvimento 
do Plano Nacional de Internet das Coisas e o Plano Nacional de Manufatura Avançada, desenvolvidos em parceria com diversos atores institucionais de todas as regiões do Brasil, para compreender o conhecimento das referidas tecnologias e aplicá-la nas firmas brasileiras.

Quanto aos resultados, pode-se constatar que as firmas investigadas tendem a impulsionar outras firmas a adotarem o processo de adoção tecnológica, em especial as firmas dentro da porteira. Vale ressaltar que ao investigar as firmas sobre o investimento em tecnologia, percebeu-se que a ideia principal no curto prazo é romper as barreiras culturais entre os elos da cadeia produtiva, quanto a adoção de tecnologias.

Destaca-se ainda que as firmas ao adotarem as tecnologias em estudo, apontaram a agregação de valor ao produto final, otimização da força de trabalho, aumento da produtividade e oportunidade de diversificação da cadeia produtiva, eficiência em custos, oportunizando melhoria na qualidade de vida da sociedade, participação dos clientes e fornecedores nos testes de protótipos, expansão e diversificação da produção, gerados pelo controle, eficiência na tomada de decisão e redução dos custos, transformando as rotinas estáticas em rotinas dinâmicas.

Foi possível também perceber que o ambiente institucional oportuniza a oferta de conhecimento, porém, nota-se uma preocupação quanto aos produtores (dentro da porteira) e as firmas pós porteira, na busca pela capacitação e qualificação para atuar com as tecnologias da indústria 4.0. Conclui-se que esforços diversos devem ser feitos por parte de diferentes atores para que o processo de adoção destas tecnologias seja mais difundido no setor e em firmas com diferentes perfis, proporcionando uma maior agregação de valor e competitividade setorial.

Entende-se que o estudo alcançou seus objetivos, porém, apresentou algumas limitações, por não abranger todas as firmas do setor e startups que adotam as tecnologias da indústria 4.0 no Rio Grande do Sul, o que limitou, também, o conhecimento sobre as demais tecnologias da indústria 4.0 mencionadas na literatura. Alguns atores institucionais como a Embrapa, Cepea /Esalq, ABDI e o Ministério da Educação, não foi obtido retorno para realizar as entrevistas. Alguns especialistas investigados não conheciam o setor do agronegócio, o que limitou o conhecimento com maiores detalhes.

Sugere-se, portanto, realizar um estudo com uma maior amostragem de firmas do agronegócio e startups; estudar de forma individual cada tecnologia da indústria 4.0 e analisar os indicadores de eficiência inovativa em comparação com as tecnologias tradicionais nas firmas do agronegócio do Rio Grande do Sul. Outra sugestão é investigar as firmas dentro da porteira, a partir das categorias abordadas neste estudo, abrangendo assim, um volume maior de informação sobre a temática para a ciência e para o setor. Salienta-se possibilidades de identificar as tendências e as possíveis escolhas das tecnologias da indústria 4.0, nas firmas pós porteira, permitindo a troca de conhecimento e experiências entre o setor, para que gradativamente, ocorra processo de adoção da tecnologia em todos os elos da cadeia.

\section{Referências Bibliográficas}

BARDIN, L. Análise de Conteúdo. Lisboa: Edições 70, LDA, 2009.

BAURER, W., et al. Transforming to a hyper-connected society and economy - towards an "Industry 4.0”. Procedia Manufacturing v. 3: p. 417 - 424. 2014.

BIERNACKI, P.; WALDORF, D. Snowball sampling: problems and techniques of chain referral sampling. Sociological Methods \& Research, Thousand Oaks, v. 10, n. 2, 1981.

BRASILALEMANHANEWS. Stihl inicia obra do seu novo centro de P\&D. Disponível em http://www.brasilalemanhanews.com.br/empresas-2/stihl-inicia-obra-do-seu-novo-centro-de-pd/. Acesso em 5 dez. 2017;

BUZZACCHI, L. et al. Technological regimes and innovation in services: the case of the Italian banking industry, Research Policy, v. 24, p.151-168, 1993.

CEMA - European Agricultural Machinery - Digital Farming: what does it really mean? 2017; 
CIO. Cios transformadores conquistam o prêmio IT leaders 2017. Disponível em

<http://cio.com.br/carreira/2017/12/06/cios-transformadores-conquistam-o-premio-it-leaders-2017/.> Acesso em 23 dez. 2017.

CORREIO DO POVO. Startups inovam vida no campo. Disponível em <http://www.correiodopovo.com.br/Noticias/Rural/Agricultura/2015/12/573883/Startups-inovam-vidano-campo> Acesso em 05 dez. 2017.

DAFT, R. L. Bureaucratic versus nonbureaucratic structure and process of innovation and change. In: BACHARACH, S. B. (Ed.) Research in the sociology of organizations. p. 129-166. Greenwich, CT: JAI Press, 1982.

DAMANPOUR, F.; EVAN, W. M. Organizational innovation and performance: the problem of organizational lag. Administrative Science Quarterly, v. 29, p. 392-409, 1984.

.The Dynamics of the adoption of product and process innovations in organizations.

Journal of Management Studies v. 38, n. 1, jan. 2001.

DRATH, R. HORCH, A. Industrie 4.0: Hit or Hype? [Industry Forum]. IEEE Industrial Electronics Magazine,v. 8, n;2), p. 56-58, 2014.

ENGSFELT, P. NORDGREN, E. Adoption of management innovations: motivation, timing and extent of implementation. University of Gotheburg. School of Business, Economics and Law. p. 1-39, 2014.

ETTLIE J. E. REZA. E.M. Organizacional Integration and Process Innovation. The Academy of Management Journal, v. 35, n. 4, p. 795-827, out. 1992.

et al. Organizational Strategy and Structural Differences for radial versus incremental innovation. Management Sci., v. 30, p.632-695. 1984.

EUROPEAN COMMISSION. Factories of the Future PPP: towards competitive EU manufacturing. 2013. Disponível em: <http://ec.europa.eu/research/press/2013/pdf/ppp/fof_factsheet.pdf.> Acesso em 12 fev. 2017.

FARZIN, Y. H.,et al. Optimal timing of technology adoption. Journal of Economic Dynamics and Control, v. 22, n. 5, p. 779-799, 1998

FRAMBACH, R;SCHILLEWAERT, N. Organizational innovation adoption: A multi-level framework of determinants and opportunities for future research. Journal of Business Research. v.55. 2002, p. 163176.

FRAUNHOFER IAO. Industry 4.0: China moves into the fast lane. 30 de março de 2015. Disponível em: <https://www. iao.fraunhofer.de/lang-en/about-us/press-and-media/1218-industry-4-0-china-movesinto-the-fast-lane.html> Acesso em 12 fev. 2017.

GOODMAN, Leo A. Snowball sampling. The Annals of Mathematical Statistics. v. 32. n. 1, p. 148$170,1961$.

HAIR JR., J.F. et al. Fundamentos de métodos de pesquisa em administração. Tradução Lene Belon Ribeiro. Porto Alegre: Bookman, 2005.

HENG, S. Industry 4.0: Huge potential for value creation waiting to be tapped. Deutsche Bank AG, Deutsche Bank Research.2014. 
JORNAL DO COMÉRCIO RS. A pulverização por Drones. Disponível em http://jcrs.uol.com.br/_conteudo/2017/08/colunas/observador/580645-a-pulverizacao-pordrones.html.>Acesso em $01 \mathrm{dez} 2017$.

KAGERMANN H. et al. Industry 4.0: With the Internet of Things on the way to the 4th industrial revolution. VDI news, 13. 2011.

Recommendations for implementing the strategic initiative Industrie 4.0: Final report of the Industrie 4.0 Working Group, 2013.

KIMBERLY A; EVANISKO, M. J. Organizational Innovation: The Influence of Individual, Organizational, and Contextual Factors on Hospital Adoption of Technological and Administrative Innovations John R.: The Academy of Management Journal, v. 24, n. 4, p. 689-713, 1981.

KRUGLIANSKAS, I;Tornando a Pequena e Média Empresa Competitiva. São Paulo, Editora IEGE; 1996;

KURFUSS, T. Office of Science and Technologiy Austria Washington, DC. Industry 4.0: Manufacturing in the United States. Disponível em: <http://ostaustria.org/bridges-magazine/item/8310industry-4-0.> Acesso em: 12 fev. 2017.

LANGLEY, Ann; TRUAX, J. A Process Study of New Technology Adoption in Smaller Manufacturing Firms. Journal of Management Studies, v. 31, n. 5, set. 1994.

LASTRES, H. M. M.; CASSIOLATO, J. E. Sistema de Inovação e Desenvolvimento: as implicações de política. Revista São Paulo em Perspectiva, v. 19, n. 1, p. 34-45, jan./mar. 2005.

LUNDVALL, B. A. National Systems of Innovation: Towards a Theory of Innovation and Interactive Learning. Londres: Pinter Publishers, 1992.

MARCONI, M. de A; LAKATOS, E. M. Fundamentos de metodologia científica. 7. ed. São Paulo: Atlas, 2010.

MARKETINGINDUSTRIAL. O que é a "internet das coisas" e o seu impacto nas indústrias Disponível em <https://www.marketingparaindustria.com.br/industria/internet-das-coisas-e-impactoindustrias/> acesso em 23 nov. 2017.

MASSINI, S; LEWIN, A. Y; GREVE, H. R. Innovators and imitators: Organizational reference groups and adoption of organizational routines. Research Policy v. 34 p.1550-1569, 2005.

MÉNDEZ, R. Innovación y desarrollo territorial: algunos debates teóricos recientes. Santiago de Chile: Revista EURE, v. 28, n. 84, 2002;

MONOSTORI, L., Cyber-physical production systems: Roots, expectations and R\&D challenges, 47th CIRP Conference on Manufacturing Systems (CMS 2014); 2014.

NELSON, R. National innovation systems: a comparative analysis. New York: Oxford University Press, 1993.

PARENTE, S. L; PRESCOTT, E. C. Barriers to technology adoption and development. Journal of Political Economy, v. 102, p.298-321. 1994.

POSADA, J. Et al. Visual Computing as a Key Enabling Techology for Industrie 4.0 and Industrial Internet. Published by the IEEE Computer Society. March-April, 2015. 
POSSAS, M. L. Economia evolucionária neo-shumpeteriana: elementos para uma integração micromacrodinâmica. Estudos Avançados, São Paulo, v. 22, n. 63, p. 281-305, 2008.

REVISTA PEQUENAS EMPRESAS, GRANDES NEGÓCIOS. Realidade aumentada chega a indústria. Disponível em <http://revistapegn.globo.com/Tecnologia/noticia/2017/08/pegn-realidadeaumentada-chega-a-industria.html,>Acesso em 15 dez. 2017.

RICHARDSON, R. J. Pesquisa social: métodos e técnicas. 3.ed. São Paulo: Atlas, 2012.

ROGERS, E. Diffusion of Innovations. The Free Press, 1994.

RUBMANN, M. et al. Industry 4.0: The Future of Productivity and Growth in Manufacturing Industries. The Boston Consulting Group. p. 5-20; 2015.

SCHEER, A. Industry 4.0: from vision to implementation. Whitepaper. Disponível em http://www.researchgate.net/publication/281447305, acesso em 30 de dez. 2016.

SCHRIJVER, R. Precision agriculture and the future of farming in Europe. Scientific Foresight Study. 2016.

SCHWAB, K. A Quarta Revolução Industrial. Tradução Daniel Moreira Miranda. São Paulo. Edipro, 2016.

SIPSAS, K. Et al. Collaborative maintenance in flow-line manufacturing environments: na industry 4.0 approach. Procedia CIRP v.55, p. $236-24,2016$.

STARA. Stara e SAP levam a tecnologias das Coisas para o Agronegócio na Agrishow. Disponível em <http://www.stara.com.br/2016/04/26/stara-e-sap-levam-a-tecnologia-das-coisas-para-o-agronegociona-agrishow/>Acesso em 12 dez. 2017.

STOCK, T.; SELIGER, G. Opportunities of sustainable manufacturing in Industry 4.0. Procedia CIRP, v. 40, p. 536-541, 2016.

TRIVIÑOS, A. N. S. Introdução à pesquisa em ciências sociais: a pesquisa qualitativa em educação. 1. ed. - 19. reimpr. - São Paulo: Atlas, 2010.

WISDOM JP, et al. Innovation Adoption: A Review of Theories and Constructs. Administration and policy in mental health.; 41, n.4: p. 480-502, 2014.

YIN, R. K. -. Estudo de caso: planejamento e métodos. 4. ed. Porto Alegre: Bookman, 2010.

ZALTMAN, G. et al. Inovations and Organizations, Wiley and Sons, New York, 1973. 